\title{
A Formação de Pedagogos(as) do Estado de Sergipe para o uso de Tecnologias Digitais Educacionais
}

\author{
Elisa Ayane Santos Paes ${ }^{1}$, Jean C. S. Rosa ${ }^{2}$, Alessandra C. M. Alves ${ }^{3}$ \\ ${ }^{1}$ Centro Universitário Maurício de Nassau (UNINASSAU) \\ Aracaju - SE - Brasil \\ ${ }^{2}$ Departamento de Ciência da Computação \\ Universidade Federal da Bahia (UFBA) \\ Salvador - BA - Brasil \\ ${ }^{3}$ Departamento de Educação \\ Faculdade de Administração e Negócios de Sergipe (FANESE) \\ Aracaju - SE - Brasil \\ elisaayane24@gmail.com, jean.rosa@ufba.br, \\ alvesalessandraedu@gmail.com
}

\begin{abstract}
Resumo. As tecnologias digitais estão em todos os lugares, inclusive na escola. Apesar dessa ubiquidade das tecnologias digitais, os pedagogos de Sergipe têm sido formados para o uso de tecnologias digitais educacionais? Para explorar respostas para esta questão, foi conduzido um questionário online, com questões aberta e fechadas, na qual houve respostas válidas de 29 estudantes de quatro Instituições de Ensino Superior de Sergipe A partir das análises realizadas nas respostas dos estudantes de Licenciatura em Pedagogia foi observado que apesar de em algumas instituições de ensino superior as disciplinas abordarem sobre as tecnologias digitais educacionais, a formação destes estudantes de pedagogia acerca desta temática é insatisfatória.
\end{abstract}

\section{Introdução}

As tecnologias digitais vêm adentrando no cotidiano das pessoas de forma expressiva. É de grande importância neste cenário que o professor saiba utilizar as tecnologias digitais educacionais (TDE) com autonomia em suas práticas educativas, tendo em vista que as propostas pedagógicas não costumam ser uma construção coletiva e participativa de toda a comunidade escolar. Esses aspectos delineiam um cenário propício ao insucesso de qualquer iniciativa nessa área e contribuem para a resistência e o descrédito acerca do uso de computadores para a mediação da aprendizagem.

As TDE são meios facilitadores dos processos de ensino e de aprendizagem. Entretanto, nem sempre são abordadas nos cursos de Licenciatura em Pedagogia. Nesse sentido, questiona-se: os pedagogos de Sergipe têm sido formados para o uso de tecnologias digitais educacionais?

Pesquisar a respeito da formação de professores reflete sobre aspectos que estão inclusos na essência da profissão. $\mathrm{O}$ interesse pelo tema deu-se devido à dificuldade em que a pesquisadora tinha no que se refere ao uso de TDE, a partir disso, foi crescendo o 
interesse em pesquisar a respeito e investigar sobre a formação dos professores para o referido tema.

É de grande importância que o professor saiba utilizar as TDE para ter mais autonomia em suas práticas educativas, para que o mesmo passe esse ensinamento para os seus alunos, e para tornar suas aulas mais atrativas, prazerosas e interessantes. Apesar de não ser levado em conta na definição inicial da pesquisa, o momento de pandemia da covid-19 vivida em 2020 torna este tema ainda mais relevante, pois, várias instituições de ensino têm se utilizado as tecnologias digitais para a condução de práticas de ensino e de aprendizagem.

Portanto, o objetivo desta pesquisa é investigar a formação de pedagogos de Sergipe para o uso de tecnologias digitais educacionais. A metodologia utilizada nesta pesquisa é de natureza mista a partir da condução de três passos metodológicos: (i) questionário com questões fechadas e abertas, (ii) análise estatística descritiva para os dados quantitativos coletados por meio das questões fechadas e (iii) análise temática para os dados qualitativos coletados por meio das questões abertas.

Este artigo está dividido em 5 seções. A seção seguinte, apresenta trabalhos relacionados que tratam sobre a formação de professores para o uso de tecnologias digitais nos cursos de pedagogia. A metodologia utilizada na pesquisa é o tema tratado a Seção 3. Por sua vez, a Seção 4 trata dos resultados encontrados, a sua análise e as discussões. Por fim, na Seção 5 são apresentadas as considerações finais da pesquisa.

\section{Formação de Professores para o uso de Tecnologias Digitais nos Cursos de Pedagogia}

Acerca da formação docente, Coracini (2010), desenvolveu a sua dissertação de mestrado em Educação em que foram analisados os Projeto Político Pedagógico (PPP) dos cursos de pedagogia de universidades federais brasileiras a fim de identificar a formação do professorado para o uso pedagógico de tecnologias digitais. Em sua pesquisa, a autora identificou que em um número significativo de cursos de pedagogia oferecem disciplinas optativas acerca do uso de tecnologias digitais. Isto indica que não há garantias, para o corpus da pesquisa da autora, que os pedagogos sejam formados para utilizarem tecnologias educacionais em suas práticas laborais [Coracini 2010].

Silva e Fuza (2017) citam que em uma investigação acerca de letramento digital em cursos de Letras de uma universidade de Londrina foi diagnosticado que não há disciplinas específicas de como utilizar as tecnologias digitais nos processos de ensino e de aprendizagem. Entretanto, é importante considerar que as tecnologias podem oferecer inúmeras possibilidades por meio da interatividade, trocas de experiências, tudo isso por meio das tecnologias digitais, contribuindo assim com o fortalecimento das metodologias de ensino e trazer melhores resultados no desempenho dos estudantes.

A revisão da bibliográfica da literatura publicada por Marfim e Perce (2017) acerca da formação do pedagogo para o uso educacional de tecnologias digitais. De acordo com os autores, mesmo sabendo da importância da inclusão das tecnologias digitais no processo de formação de professores, as universidades têm contribuído de forma retraída com a experiência formativa no que se diz respeito a tecnologias digitais, deixando em segundo plano e distante das demandas atuais no contexto sociocultural. Este resultado é apontado a partir da revisão da literatura científica publicada entre os anos de 2006 e 2014. 
Por sua vez, Marfim e Pesce (2020) publicaram um novo artigo em que apresentam um estudo de caso em uma universidade brasileira e constataram que existe a necessidade da incorporação das tecnologias digitais nos processos de ensino e de aprendizagem, os formandos em Pedagogia expressam a ausência de um processo formativo que proporciona que as tecnologias digitais estejam intimamente relacionadas com as práticas socioculturais que envolvem os processos de ensino e de aprendizagem.

Tratando especificamente sobre a Universidade Federal de Sergipe (UFS), Santa Rosa (2019) realizou um estudo documental no ementário dos cursos de licenciatura da instituição. No estudo, a autora identificou que o curso de Pedagogia possui uma disciplina obrigatória específica para tratar sobre as TDE, chamada de "Educação e Tecnologias da Informação e Comunicação". Ainda que o curso de Pedagogia da UFS possua esta disciplina, Santa Rosa (2019) conclui a sua dissertação indicando a necessidade de atualização dos currículos de todas as licenciaturas da UFS, incluindo a de Pedagogia, para contemplar as TDE.

Nesse sentido, ao considerar o contexto apresentado nesta subseção é possível identificar que desde o início dos cursos Pedagogia não houve uma exploração das tecnologias digitais tanto na formação quanto no favorecimento do uso de tecnologias digitais para enriquecer os processos de ensino e de aprendizagem. Mesmo sabendo da importância e do contexto contemporâneo, da ubiquidade das tecnologias digitais, vários cursos de Pedagogia não englobam o uso das tecnologias digitais em seus processos formativos.

\section{Metodologia}

A pesquisa apresentada neste artigo possui a natureza mista, combinando métodos qualitativos e quantitativos. Sob essa perspectiva, para atingir os objetivos da pesquisa foi determinado os passos metodológicos, a saber: (i) questionário com questões fechadas e abertas [Coelho, Souza e Albuquerque 2020], (ii) análise estatística descritiva [Sassi, 2020] para os dados quantitativos coletados por meio das questões fechadas e (iii) análise temática [Braun e Clarke 2006] para os dados qualitativos coletados por meio das questões abertas.

De acordo com a plataforma e-MEC ${ }^{1}$, base de dados oficial dos cursos e Instituições de Ensino Superior (IES) mantida pelo Ministério da Educação do Brasil (MEC), existem de IES que oferecem o curso de pedagogia presencialmente em Sergipe. Por considerar a quantidade de IES o escopo da pesquisa foi limitado, passando a considerar somente as instituições Aracaju e São Cristóvão (capital e região metropolitana), resultando em dez IES para esta pesquisa. Ainda assim, reduziu-se por conveniência as IES resultando em quatro instituições ${ }^{2}$. O conjunto de IES consideradas nesta pesquisa são apresentadas no Quadro 1.

\footnotetext{
${ }^{1}$ Pesquisa realizada em 22 de setembro de 2020.

${ }^{2}$ Os nomes e siglas das IES foram omitidos devido a aspectos éticos.
} 
Quadro 1. Conjunto de IES desta pesquisa.

\begin{tabular}{|l|c|l|}
\hline \multicolumn{1}{|c|}{ IES } & Sigla & Cidade \\
\hline Centro Universitário A & UA & Aracaju \\
\hline Faculdade B & FB & Aracaju \\
\hline Universidade C & UC & São Cristóvão \\
\hline Universidade D & UD & Aracaju \\
\hline
\end{tabular}

A partir da escolha das IES foi construído o questionário. Questionário é um instrumento de coleta de dados composto por perguntas para mensurar ou quantificar atributos ou características de um objeto de pesquisa [Coelho, Souza e Albuquerque 2020]. Para esta pesquisa foi produzido um questionário com perguntas fechadas e abertas. Foram convidados a responder o questionário somente estudantes do curso de Licenciatura em Pedagogia que estavam cursando do sexto semestre letivo ou posterior das quatro IES. O convite foi realizado por meio de listas de e-mails e grupos de WhatsApp no qual os participantes deveriam responder um formulário do Google Forms.

A partir das respostas a cada pergunta do questionário foi realizada uma análise referente ao tipo do dado. Para as questões fechadas foi realizada a análise estatística descritiva. Para as questões abertas foi realizada a análise temática. De acordo com Sassi (2020), por meio da estatística descritiva é possível sintetizar os dados quantitativos em gráficos ou diagramas. Considerando que os dados quantitativos coletados variavam entre três opções (sim, não e talvez), cada categoria estatística representa as respectivas frequências de cada resposta. Portanto, foram utilizados gráficos de setores (ou os popularmente chamados de gráficos de pizza ou em barras).

Por sua vez, para analisar os dados qualitativos foi utilizada a análise temática. A análise temática é uma técnica de análise de dados apresentada por Braun e Clarke (2006) em que é possível organizar e descrever um conjunto de dados que foram codificados e categorizados em temas. Para isso, a análise é dividida em seis etapas.

$\mathrm{Na}$ primeira etapa da análise temática foi realizada a familiarização com os dados advindos do questionário. Nesse momento todos os dados foram lidos e ideias iniciais foram obtidas para responder à questão de pesquisa proposta. Na segunda etapa ocorreu a geração inicial de códigos, em que os dados foram codificados. Na terceira etapa os códigos foram agrupados em temas, por exemplo: críticas, recursos, características. É importante destacar que na análise dos dados a criação dos temas foi realizada a posteriori à codificação. Sendo assim a análise caracteriza-se como bottonup. Na quarta etapa foi realizada uma refinação dos temas, em que alguns dos temas foram divididos ou agrupados. A quinta etapa destinou-se a revisão dos títulos dos temas e sua consolidação. Por fim, a última etapa é a escrita de textos para publicação científica. 
De acordo com Lakatos e Marconi (2017), toda pesquisa que envolve humano deve considerar aspectos éticos e tomar algumas ações para assegurar que a pesquisa será conduzida de forma ética. Nesse sentido, considerando que houve a participação de humanos nesta pesquisa, algumas ações foram tomadas para fundamentar os aspectos éticos desta pesquisa, a saber: a solicitação do consentimento livre e esclarecidos dos participantes e o sigilo profissional requerido em pesquisa científica.

\section{Análise dos Resultados}

A finalidade desta etapa da pesquisa é analisar os dados coletados por meio de questionário, a fim de interpretar as respostas referentes ao assunto. Nesta direção, através das leituras e das respostas obtidas foram construídos conhecimentos que possibilitaram explorar o objeto desta pesquisa. Sendo assim, foi utilizada a análise estatística descritiva [Sassi 2020] para os dados quantitativos e a análise temática [Braun e Clark 2006] para os dados qualitativos.

O questionário desta pesquisa ficou disponível para respostas de 07 de outubro de 2020 até 08 de novembro de 2020. Foram obtidas 50 respostas de estudantes de pedagogia das quatro IES de Sergipe. Entretanto, somente as respostas de 29 estudantes foram consideradas válidas para esta pesquisa, pois algumas respostas foram repetidas e alguns dos respondentes não estavam matriculados no sexto semestre do curso ou posterior. Portanto, o corpus do estudo é composto pelas 29 respostas válidas ao questionário. A distribuição das instituições de vínculo dos estudantes participantes é apresentada no gráfico da Figura 1.

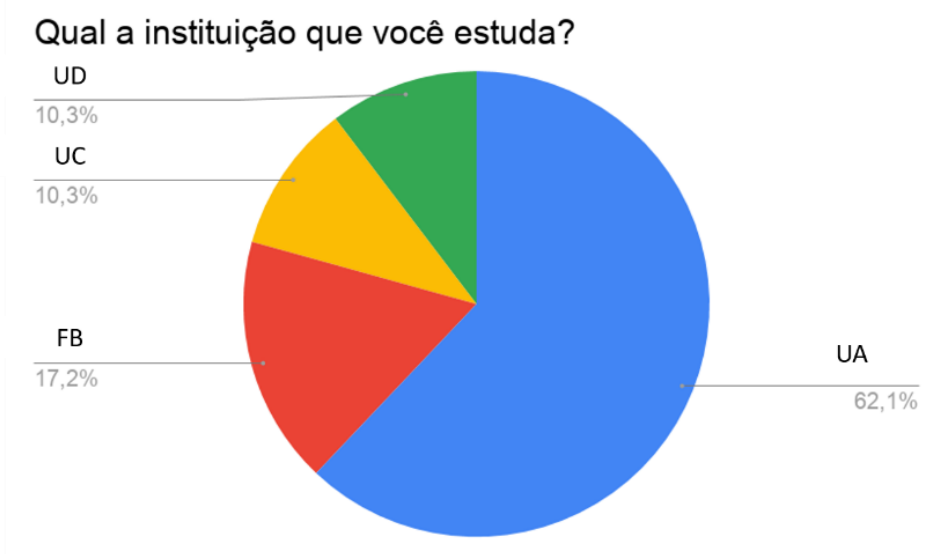

Figura 1. Gráfico relacionado à distribuição de participantes por IES.

Com relação ao semestre de cada estudante, todos os participantes vinculados a UD e a FB estavam matriculados no sétimo semestre do curso; todos os participantes vinculados a UC estavam matriculados no sexto semestre; e 9 dos 18 participantes vinculados a UA estavam matriculados no oitavo semestre e os demais 9 participantes da UA estavam matriculados no sexto semestre. Nesse sentido, a maior parte dos respondentes do questionário estavam matriculados no sexto semestre do curso, seguido de pessoas matriculadas no oitavo e no sétimo semestre, respectivamente.

Com relação a pergunta "em alguma disciplina do seu curso foi abordado acerca do uso de TDE?", a maioria dos respondentes indicaram que as TDE foram abordadas em alguma disciplina do curso de pedagogia da sua IES. Entretanto, é válido destacar que cerca de $41 \%$ dos respondentes indicaram que as TDE não foram 
abordadas em seus cursos. Detalhando melhor estes resultados e descrevendo a partir das classificações por IES, todos os estudantes da UC indicaram que as TDE foram temas de alguma das disciplinas do seu curso. Todavia, todos os estudantes da UD indicaram que as TDE não foram temas de alguma das disciplinas do seu curso.

Com relação a UA e a FB, não houve harmonia entre os resultados. Isto reflete que nem todos os participantes da pesquisa que são vinculados a UA e a FB perceberam que em algumas disciplinas do curso de pedagogia a temática das TDE estavam presentes. A Figura 2 ilustra o gráfico acerca dessa percepção dos participantes.

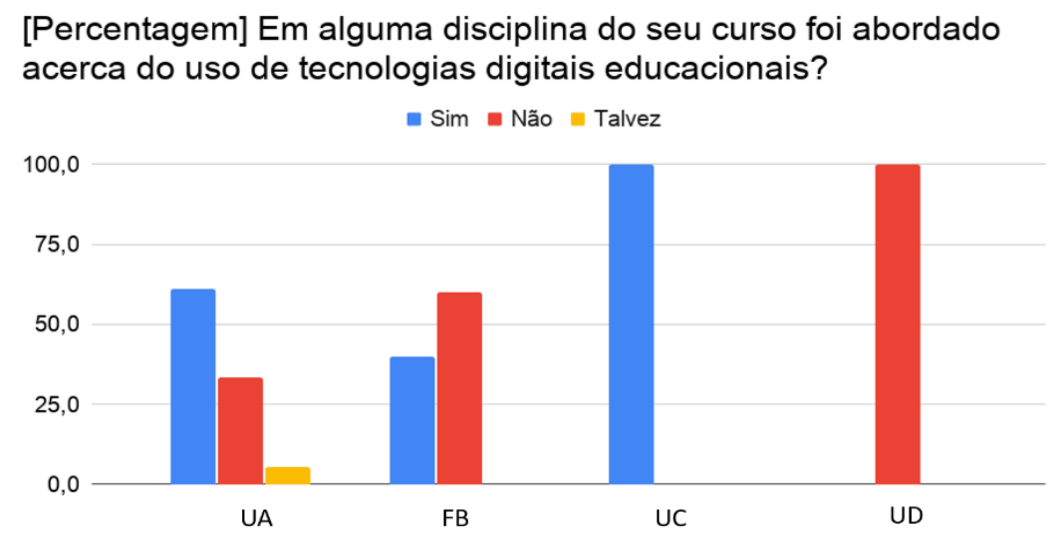

Figura 2. Gráfico relacionado às TDE como temática de disciplinas do curso.

Para os participantes que responderam que as TDE foram abordadas em alguma disciplina do curso, foi questionado qual o nome da disciplina, três pessoas não responderam ou indicaram não lembram. Os estudantes da UA indicaram que as TDE foram abordadas nas seguintes disciplinas: metodologia da pesquisa, educação e tecnologia, cultura organizacional, tópicos integradores I e II e educação de jovens e adultos. Por sua vez, das respostas positivas da FB, apenas uma indicou que a disciplina educação e as tecnologias de informação e comunicação contém a temática das TDE. Por fim, os estudantes da UC indicaram que a disciplina educação e tecnologia da informação e da comunicação e a disciplina teorias da educação e comunicação.

A partir dessas respostas foi pedido que os participantes descrevessem sobre o que foi tratado na disciplina. Para analisar as respostas, por serem de natureza qualitativa, foi utilizada a análise temática. A partir da condução da análise temática foi possível identificar dois temas (características da disciplina e críticas) e dois subtemas (subtemas relacionados ao tema características da disciplina: temas abordados $\mathrm{e}$ recursos). A Figura 3 ilustra os temas e subtemas.

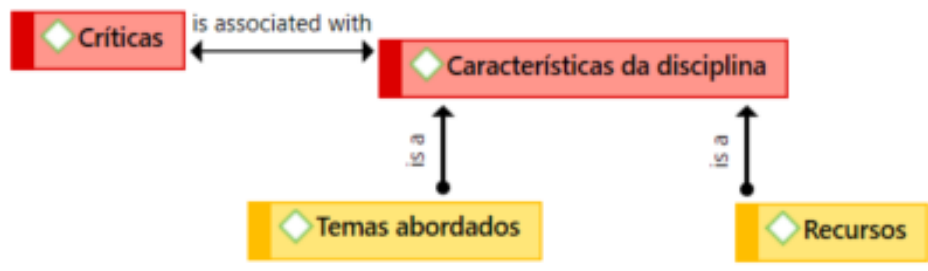

Figura 3. Diagrama que representa os temas (destacados em vermelho) e os subtemas (destacados em amarelo) resultantes da análise temática. 
O tema intitulado "características da disciplina" possui dois subtemas. O subtema que reflete as características da disciplina são os "recursos". De acordo com os participantes, nas disciplinas que cursaram, dois recursos foram utilizados: a atividade stopmotion e um grupo no Facebook®. O subtema "temas abordados" categorizou uma série de temas que foram ministrados durante as disciplinas relatadas pelos estudantes participantes da pesquisa. O Quadro 2 apresenta as categorias de temas abordados durante as disciplinas.

Quadro 2. Temas abordados nas disciplinas indicadas pelos participantes.

\begin{tabular}{|c|c|}
\hline \multicolumn{2}{|c|}{ Temas abordados } \\
\hline Metodologias para o uso de tecnologias & Sobre os computadores \\
\hline A contribuição da tecnologia na educação & Tecnologia e metodologia \\
\hline Avanços tecnológicos & Metodologias ativas \\
\hline O contexto atual & Como inserir tecnologias nas aulas \\
\hline A influência na interação social por meio da comunicação & Internet \\
\hline Produção de vídeos & Muita coisa interessante para o futuro \\
\hline Debates sobre o assunto & Ensino híbrido \\
\hline
\end{tabular}

Além desses dois subtemas foi identificado que, de acordo com a participante Mi., por meio da disciplina "conhecemos a importância da tecnologia na sala de aula e no cotidiano” e, segundo M. S., "[...] as TICs na educação [...] tornará a aula mais proveitosa”. M. S. ainda aponta que o uso das tecnologias digitais na educação "levará o aluno a ser um pesquisador, ter autonomia e ser protagonista [da construção do seu conhecimento]". É válido destacar que Mi. é estudante da FB e M. S. é estudante da UA. Por fim, ainda como característica da disciplina, Ke., estudante da UC, aponta que “[a] disciplina no primeiro momento foi muito teórica". Isto que foi relatado por Ke. além de ser uma característica da disciplina, também é uma crítica, assunto do próximo tema da análise.

O tema "críticas" é composto por várias categorias. Inicialmente foi identificado que dois dos três participantes da pesquisa que são vinculados da UC indicaram que faltou a parte prática da disciplina, pois, conforme abordado anteriormente, a disciplina "foi muito teórica".

Nesse sentido, segundo Ke., estudante da UC, "o curso de pedagogia deve oferecer uma disciplina ou melhorar a metodologia da disciplina”. Não só Ke. percebe essa necessidade. P. R. S., da FB faz o seguinte comentário: "[é necessário] uma matéria específica que abordasse como usar essa tecnologia no âmbito educacional ficou vaga". De fato, os participantes consideram uma disciplina que trate sobre as TDE importante. Ke., inclusive, reconhece que "as escolas estão procurando professores com habilidades com tecnologia", todavia, segundo a participante, "não recebemos essa capacitação no ensino superior".

É importante também salientar que os participantes consideram que a disciplina cursada foi importante e reconhecem que as TDE é uma temática importante na 
formação do pedagogo. Entretanto, segundo Ke., indica que "nem sempre sabemos como utilizar [TDE]", bem como que sentiu dificuldade em usar as tecnologias propostas na disciplina, assim como a participante P. R. S.

A questão posterior foi a seguinte: Você já estagiou (obrigatoriamente ou não)? Dos 29 participantes da pesquisa, somente dois indicaram que não estagiaram, ambos da FB. Para os participantes que responderam sim à questão supra, foi questionado (i) "se durante o estágio você fez uso de TDE" ( $c f$. Figura 4) e (ii) "se em algum momento você teve dificuldade com o uso de TDE".

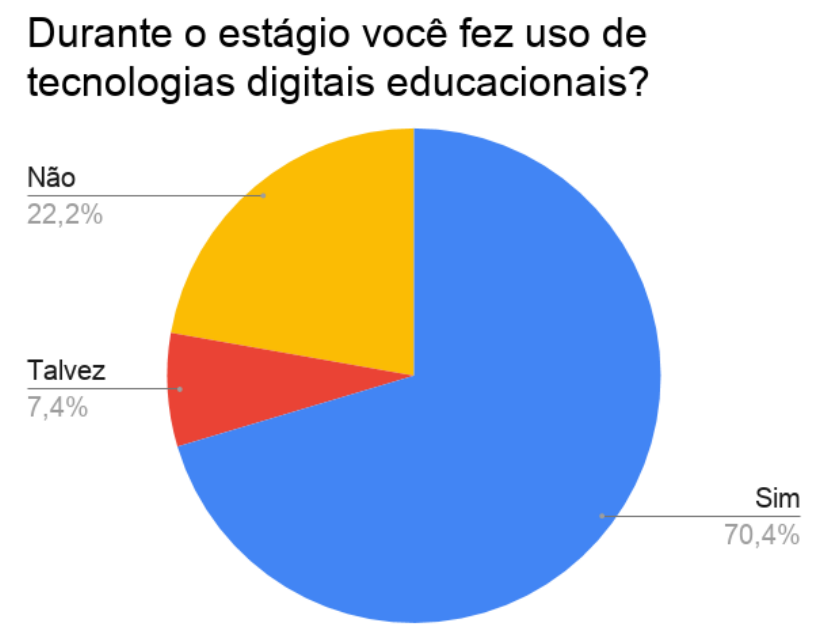

Figura 4. Gráfico que indica a quantidade de estudantes que fizeram uso de TDE durante o estágio.

A maioria dos participantes indicaram que utilizaram TDE durante o seu estágio. Além disso, a maioria dos participantes também indicaram que algum momento durante o estágio foi sentido dificuldade com o uso de tecnologias digitais educacionais, $\mathrm{o}$ gráfico da Figura 5 ilustra as destas respostas.

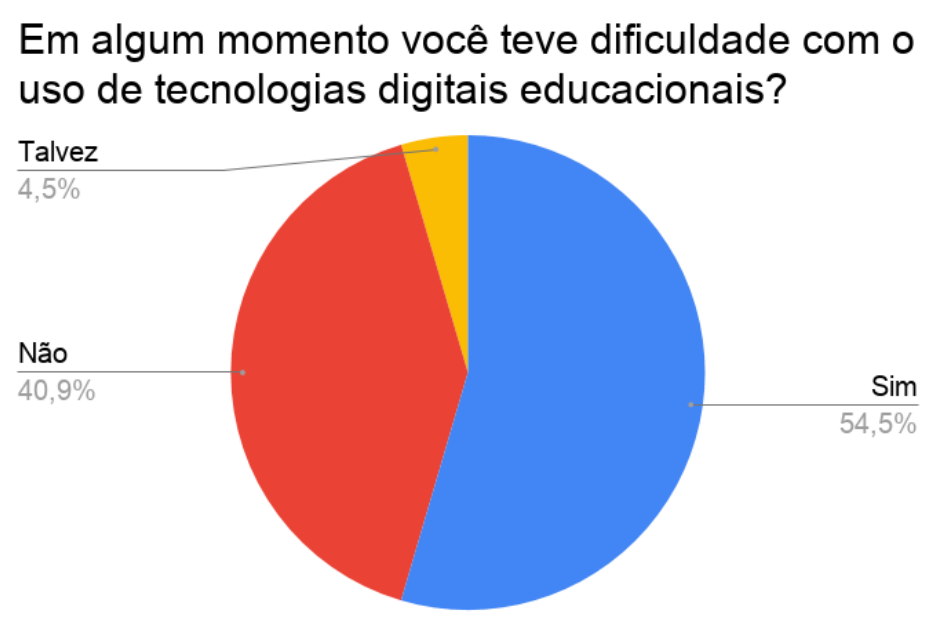

Figura 5. Gráfico que aponta se os participantes da pesquisa tiveram dificuldades com o uso de TDE durante o estágio. 
A próxima questão foi a seguinte: "você sentiu falta de alguma formação acerca do uso de TDE?". Cerca de $75 \%$ dos participantes indicaram que sim. É possível considerar a partir deste número que é uma grande parte a amostra dos participantes sentem falta da formação mesmo a maioria dos participantes tendo indicado que durante o seu curso as TDE foi tema de alguma disciplina ( $c f$. Figura 6).

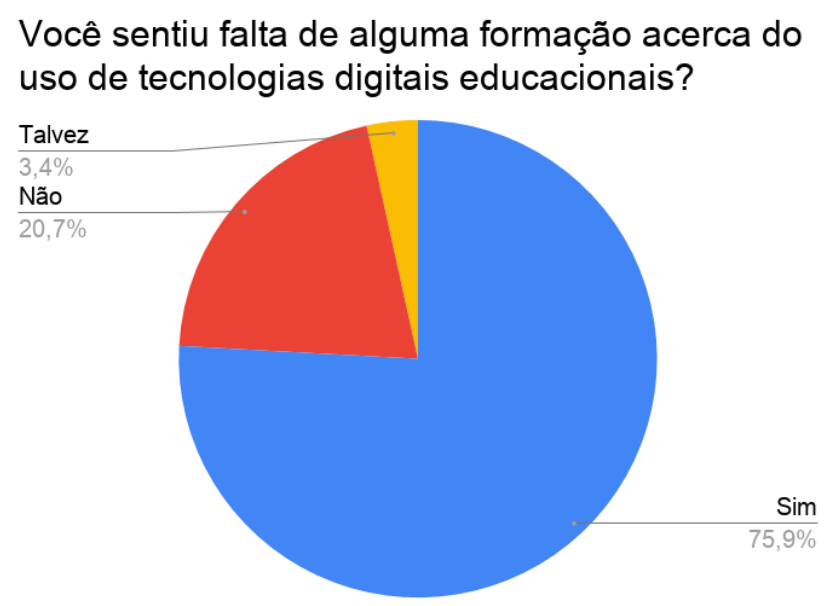

\section{Figura 6. Gráfico que aponta se os participantes sentiram falta de alguma formação} acerca do uso de TDE.

Para finalizar o questionário, os participantes responderam a seguinte pergunta: "você se considera aptalo a utilizar TDE durante sua prática pedagógica em sala de aula?" os participantes se dividiram entre as três respostas indicadas: o sim, o não e o talvez. Somente cerca de $34 \%$ afirmam que se consideram aptos a utilizar as TDE durante a sua prática pedagógica de sala de aula. Os demais cerca de $65 \%$ dividem-se entre o não (com 34,5\%) e o talvez (com 31\%).

Considerando as análises dos dados qualitativos e quantitativos é possível compreender que alguns participantes tiveram formação acerca das TDE. Entretanto, essa formação foi insatisfatória. Este resultado alinha-se aos resultados das pesquisas apresentadas por Marfim e Pesce (2020), Coracini (2010), Silva e Fuza (2017) e Santa Rosa (2019).

Nesse sentido, é possível observar que apesar da necessidade de formação do Licenciado em Pedagogia para o uso de TDE ser algo amplamente aceito, divulgado e compreendido, para os participantes desta pesquisa, a UA, a FB, a UC e a UD realizam essa formação insatisfatoriamente. Ao considerar isso, em tempos de pandemia de covid-19, com a mudança no modelo de ensino presencial para o ensino remoto, os pedagogos podem ter sofrido mais ainda pela falta de formação em TDE. É válido destacar que isto também reflete na aprendizagem e na construção do conhecimento do estudante.

\section{Considerações Finais}

A partir destes resultados foi possível compreender como os 29 participantes da pesquisa percebem a sua formação para o uso de tecnologias digitais. Participantes de 3 instituições responderam que tiveram em alguma disciplina algo relacionado às TDE. 
Estudantes da UD foram os únicos e unânimes a indicarem que não tiveram essa temática em seu percurso formativo.

Os estudantes da UA, FB e UC indicaram vários temas relacionados às TDE que foram abordados durante os seus cursos. Entretanto, várias críticas foram estabelecidas, principalmente com relação ao caráter não prático da disciplina cursada e a metodologia adotada pelos professores. Outrossim, a grande maioria ( 70\%) dos participantes utilizaram TDE durante seus estágios (sejam eles obrigatórios ou não), dos quais, mais da metade $(\sim 54 \%)$ indicaram que tiveram dificuldades.

É impressionante o número de participantes ( $75 \%)$ que indicaram que sentiram falta de as TDE serem abordadas em sua formação. Ao considerar os resultados anteriores com este foi identificado indícios de que apesar de as IES terem disciplinas que tratam sobre TDE em seus currículos (exceto a UD), a temática ainda foi abordada de forma insatisfatória. Estes indícios são clarificados ao serem observados considerando que somente cerca de $34 \%$ dos participantes se consideram aptos a utilizarem TDE em suas práticas pedagógicas em sala de aula.

Respondendo à questão norteadora da pesquisa, de acordo com as análises realizadas nas respostas de 29 estudantes de Licenciatura em Pedagogia das IES UA, FB, UC e UD foi observado que apesar de em algumas IES disciplinas abordam sobre as TDE, a formação destes estudantes de pedagogia é insatisfatória.

Portanto dentre deste contexto, faz-se necessário o aprimoramento da formação continuada, que deverá sempre considerar as reformulações curriculares que traz em seu bojo a promoção da inovação profissional, a elevação da qualidade dos cursos do magistério, e a valorização da carreira do professor. A pesquisa apresentada neste artigo não esgota sua essência investigativa e exploratória, permitindo outros estudos e análises que ampliem a temática para em questão.

\section{Referências}

Braun, V. and Clarke, V. (2006) Using thematic analysis in psychology. Qualitative Research in Psychology, 3 (2), 77-101. doi: 10.1191/1478088706qp063oa

Coelho, J. A. P. M., Souza, G. H. S. and Albuquerque, J. (2020) Desenvolvimento de questionários e aplicação na pesquisa em Informática na Educação. In: Jaques, P. A.; Siqueira; S.; Bittencourt, I.; Pimentel, M. (Org.) Metodologia de Pesquisa Científica em Informática na Educação: Abordagem Quantitativa. Porto Alegre: SBC.

Coracini, E. G. R. (2010) A formação de professores para o uso das tecnologias digitais nos cursos de pedagogia. Dissertação (Mestrado em Educação). Universidade do Estado de Santa Catarina, 2010.

Lakatos, E. M. and Marconi, M. A. (2017) Fundamentos de Metodologia Científica. São Paulo: Atlas.

Marfim, L. and Pesce, L. (2017) Formação do pedagogo para o uso educacional das tecnologias digitais de informação e comunicação: uma revisão de literatura (20062014). Laplage em Revista, 3 (2), 9-23.

Marfim, L. and Pesce, L. (2020) Formação inicial do pedagogo para integrar as TDIC às práticas educativas: um estudo de caso. Revista Eletrônica de Educação, 14, 1-20. doi: $10.14244 / 198271992544$ 
Sassi, G. P. (2020) Introdução à Estatística Descritiva para pesquisas em Informática na Educação. In: Jaques, P. A.; Siqueira; S.; Bittencourt, I.; Pimentel, M. (Org.) Metodologia de Pesquisa Científica em Informática na Educação: Abordagem Quantitativa. Porto Alegre: SBC.

Santa Rosa, J. R. O. (2019) Formação Docente Frente às Tecnologias Digitais da Informação e da Comunicação: o caso dos Cursos de Licenciatura da Universidade Federal de Sergipe - Campus São Cristóvão. Dissertação (Mestrado em Educação) Universidade Federal de Sergipe.

Silva, I. C. S. and Fuza, A. F. (2017) Tecnologias digitais na formação de professores em Letras. Trem das Letras, 3 (1), 137-161. 